\title{
The Revival of a Traditional Engineering - New Trends in Geotechnical Engineering Research
}

\author{
Wing Shun Kwan* \\ Department of Civil Engineering, California State University, Los Angeles, USA
}

Received: 眥 February 05, 2018; Published: 䡒 February 13, 2018

*Corresponding author: Wing Shun Kwan, Department of Civil Engineering, California State University, Los Angeles, USA

\section{Introduction}

Geotechnical engineering designs are always laid as the most fundamental and earliest phase of civil engineering projects. The birth of geotechnical engineering is very hard to define, but modern geotechnical engineering practice is generally recognized beginning in 1925 after Professor Karl Terzaghi's publication of Erdbau mechanik, which demonstrates the framework of the principle of effective stress. About a century later, the field of geotechnical engineering is still considered relatively young and full of wonders about the growing challenges upfront. The geotechnical engineering profession is challenged by increasing civil material consumption and aging infra-structures to meet the growing population worldwide in the coming century. The basic infrastructures of civilization are outdated, including roads, bridges, underground tunnels, airport facilities, waterways, and dams. Past's Geo-techniques for natural hazard assessment, energy supply, skyscraper, transportation, and land use are not sufficient for future's challenges. Because of unfit land-use models, population growth and climate change, more people and lands are jeopardized by the risk of natural disasters, such as earthquakes and flooding. This article documents a few breakthroughs the recent geotechnical research has attempted to advance the "old technologies" to meet the upcoming challenges.

Performance-based seismic risk analysis (or Performancebased Earthquake Engineering, PBEE) was introduced about 50 years ago, and has become increasingly popular in the past decade. PBEE incorporates all possible information and quantifies uncertainties with probabilities from all stakeholders (seismologists, civil engineers, loss analysts, and owners) to predict the seismic performance in terms of a risk level expressed in terms of dollar loss or other measures that the public can easily comprehend, instead of expressing the results in a form of factor of safety [1]. Started in structural engineering, the modulatable PBEE framework has been gaining more attention in the application of geotechnical engineering, particularly in the soil liquefaction evaluation [2]. In fact, the performance-based seismic risk analysis could be extendedto other kinds of hazard evaluation. The risky-based framework provides more descriptive and accurate engineering analysis than the traditional deterministic type of analysis (e.g. factor of safety). It is a better presentation of risk.

Geo-material strength characterization is one of the most important yet challenging components in civil engineering projects. The future requires characterization extending to boarder range of materials such as municipal waste, gas hydrates, and soils from extreme off-shore recovery. Geo-material shear strength indicates the ability of the ground to withstand alteration in stresses, and very likely required to deal with great variability that the in-situ structure and fabric inherited from the natural depositional process. Investigating geo-material's shear strength through field or laboratory methods has been practiced for more than half century and become an un separated part of any civil engineering project. Nevertheless, research in geo-material testing remains immature to meet the construction challenges for the new century such as testing to an extreme material (either too weak or too stiff) and with applications of more complicated loading patterns. More importantly, increasing the reliability (i.e., decreasing uncertainty) of test results is always desirable. Field testing has advanced greatly by adopting geophysics methods. Recent study has successfully established shear wave velocity profiles that are over 500 meters deep at complex inter-bedded geology environment [3]. On the other hand, geotechnical laboratory testing has also advanced significantly in the past two decades. Building on top of the success of automation from the decades of 2000-10, the newly developed bench-top type of commercial apparatus can impose 'user-defined' loading to simulate complicated loading such as an earthquake ground motion [4] or storm loading. This advancement goes beyond the conventional harmonic type of cyclic loading to achieve more realistic and specific simulation of natural hazards.

Geo-material strength characterization is typically required to obtain high-quality samples for laboratory testing. While undisturbed cohesive soil samples can be easily obtained by 
conventional tube sampling procedures, sand and other cohesion less samples cannot be retrieved at a reasonable cost. Therefore, sand specimens are commonly prepared by the reconstitution representative samples of sandy soils collected from fields for both purpose of practice and research. In the past three decades, numerous research projects were performed to identify the best reconstitution method(s) for recreating sand elements that can represent the soil fabric to simulate the field soil responses. However, past studies have shown that there is no perfect reconstitution method, and therefore uncertainties and conservatism are usually embedded in designs when sand sample laboratory test results are involved. Lately, emerging field techniques such as Gel-Push [5] and Pressure-Core [6] methods have reduced the cost of retreating undisturbed sand samples and natural hydrate bearing sediments. Those developing methods could potentially change the perception toward geo-material laboratory tests of the current practice.

The new century is bringing along many challenges but also unparalleled opportunities in geotechnical engineering research. This article includes a few of many trends of recent geotechnical research scopes that are addressing the upcoming needs of the new era. Increasing needs for energy, effects of population growth, maintenance of aging infrastructure, shrinking waste management options, environmental degradation, and threats from natural disasters should all be noted in the agenda. Moreover, there will be a need to agglomerate various types of data sets that are acquired lately due to the breakthrough of sensors technologies. Those data sets could give new insights in geo-technics using new data science. The profession of geotechnical engineering needs to focus on building more sustainable and resilient urban environments, gives prominence to the values it could contribute to the society, and constantly reinvent the technology through innovative research projects to address any pressing need and challenge.

\section{References}

1. Krawinkler H (2002) A General Approach to Seismic Performance Assessment. Proceedings of the International Conference on Advances and New Challenges in Earthquake Engineering Research, pp. 173-180.

2. Kramer SL (2014) Performance-based design methodologies for geotechnical earthquake engineering. Bulletin of Earthquake Engineering 12(3): 1049-1070.

3. Teague D, Cox B, Bradley B, Wotherspoon L (2018) Development of Deep Shear Wave Velocity Profiles with Estimates of Uncertainty in the Complex Inter-Bedded Geology of Christchurch. Earthquake Spectra, New Zealand.

4. Kwan WS, Sideras SS, Kramer SL, Mohtar CE (2017) Experimental Database of Cyclic Simple Shear Tests Under Transient Loadings. Earthquake Spectra 33(3): 1219-1239.

5. Chiaro G, Kiyota T, Umehara Y, Hosono Y, Yagiura Y, et al. (2015) Evaluation of cyclic resistance of high quality undisturbed Chiba silty sand samples retrieved by 'gel-Push' sampling technique. $15^{\text {th }}$ Asian Regional Conference on Soil Mechanics and Geotechnical Engineering, New Innovations and Sustainability, pp. 1154-1159.

6. Carlos Santamarina J, Dai S, Jang J, Terzariol M (2012) Pressure core characterization tools for hydrate-bearing sediments. Scientific Drilling (14): 44-48.

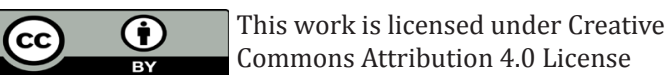

To Submit Your Article Click Here:

Submit Article

DOI: 10.32474/TCEIA.2018.01.000114

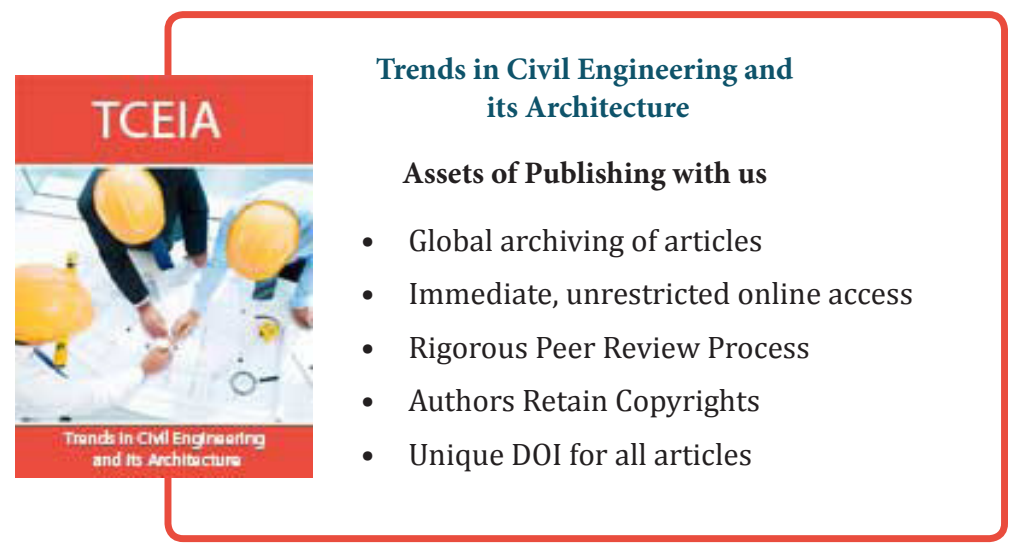

